\title{
Intervenção em habilidades metafonológicas em estudantes do ensino fundamental e desenvolvimento de leitura
}

(Intervention in metaphonological skills in elementary school students and reading development)

(Intervencion sobre habilidades metafonologica;s en los estudiantes de la educación básica y desarrollo de la lectura)

\section{Natália Martins Dias \\ Cássia Aparecida Bighetti ${ }^{* *}$}

\begin{abstract}
Resumo
Investigou-se a eficácia de um procedimento de intervenção sobre habilidades metafonológicas, implantado pela professora, em desenvolver habilidades de leitura em estudantes da 1a série. Participaram 1 professora e 59 crianças de duas classes de $1^{\text {a }}$ série (Grupo Experimental - GE; Grupo Controle - GC) do ensino fundamental de uma escola pública do interior de São Paulo. Utilizou-se de procedimento para desenvolver consciência fonológica e ensinar correspondências grafofonêmicas e, para avaliação pós-intervenção, o "Teste de Competência de Leitura de Palavras e Pseudopalavras" (TCLPP). A própria professora implantou as atividades no GE, por 15 a 20 minutos diários. O GE desempenhou-se melhor que o GC no TCLPP total e em praticamente todos os subtestes. Diferenças significativas entre os grupos foram evidenciadas em TCLPP total e subteste de trocas fonológicas. resultados revelam a eficácia das instruções fônicas, aplicadas pela própria professora em contexto de sala de aula, no desenvolvimento da habilidade de leitura de seus alunos.
\end{abstract}

Palavras-chave: consciência fonológica; leitura e escrita; intervenção.

\begin{abstract}
It investigated the efficacy of an intervention procedure on metaphonological abilities, implemented by the teacher, in develop reading abilities in 1 st grade students. Participated one teacher and 59 children of two classes of $1^{\text {st }}$ grades (Experimental Group - EG; Control
\end{abstract}

\footnotetext{
Texto recebido em setembro de 2008 e aprovado para publicação em outubro de 2009.

Psicóloga, mestra e doutoranda pelo Programa de Pós-graduação em Distúrbios do Desenvolvimento - Universidade Presbiteriana Mackenzie, bolsista FAPESP. E-mail: natalia_mdias@yahoo.com.br.

* Doutoranda pelo Programa de Pós-graduação Stricto Sensu em Psicologia da Universidade São Francisco, professora do curso de Psicologia da Universidade São Francisco - USF. E-mail: cassiapsico@mpc.com.br.
} 
Group - CG) of the elementary of a public school of the interior of SP. It was utilized a procedure for develop phonological awareness and teach write-phonemics correspondences and, for assessment post-intervention, the Teste de Competência de Leitura de Palavras e Pseudopalavras (TCLPP). The own teacher implemented the activities in the GE, for 15 to 20 daily minutes. The GE performed better that the GC in the TCLPP total and in practically all subtests. Significant differences between the groups were shown in TCLPP total and change phonological subtest. Results reveal the efficacy of the phonic instructions, applied by the own teacher in classroom context, in the development of the reading ability of his students.

Keywords: phonological awareness; reading and written; intervention.

\section{Resumen}

Fue investigada la eficacia de un procedimiento de intervención sobre habilidades metafonologicas, ejecutada por el profesor, en desarrollar habilidades de la lectura en estudiantes de la $1^{\text {a }}$ serie. Participaron 1 profesor y 59 niños de dos clases de $1^{\text {a }}$ serie (Grupo Experimental - GE; Grupo Control - GC) de la educación básica de una escuela pública del interior de São Paulo. El procedimiento fue utilizado para desarrollar conciencia fonologica y para enseñar correspondencias grafo-fonemicas y, para evaluación pos-intervención, lo Teste de Competência de Leitura de Palavras e Pseudopalavras (TCLPP). El propio profesor ejecutó las actividades en GE, por los 15 a los 20 minutos diarios. El GE obteneron mejor desempeño que el GC en el PCLPP total y prácticamente en todos las subpruebas. Las diferencias significativas entre los grupos fueron evidenciadas en el PCLPP total y subpruebas de los cambios fonologicos. Los resultados revelan la eficacia de las instrucciones fónicas, aplicados por el propio profesor en el contexto de la sala de clase, en el desarrollo de la capacidad de la lectura de sus alumnos.

Palabras Clave: conciencia fonológica; lectura y escritura; intervención.

\section{Introdução}

A relação entre habilidades de linguagem oral, tal como a consciência $A$ fonológica, e a aquisição da linguagem escrita já é fato documentado na produção científica da área (Aaron, Joshi \& Quatroche, 2008; Capovilla \& Capovilla, 2004a; Capovilla \& Dias, submetido; França, Wolff, Moojen \& Rotta, 2004) e, analogamente, estudos experimentais, nacionais e internacionais, têm provido evidências de que intervenções cujo objetivo é desenvolver habilidades de consciência fonológica podem promover ganhos significativos em habilidades de leitura e escrita (Baker \& Bernhardt, 
2004; Capovilla \& Capovilla, 2004a, 2004b; Santos, 1996; Shaywitz, 2006; Temple \& cols., 2003). Além, há evidências de que habilidades de consciência fonológica são positiva e significativamente relacionadas ao desempenho acadêmico nas séries iniciais do ensino fundamental (Capovilla, Dias \& Montiel, 2007).

Esses fatos impõem algumas consequências importantes à educação, mais especificamente à alfabetização, uma vez que trazem justificativas empíricas, oriundas de pesquisas cientificamente fundamentadas, que ratificam a eficácia de intervenções baseadas no desenvolvimento de habilidades metafonológicas não só na remediação (Capellini, Padula \& Ciasca, 2004; Capovilla \& Capovilla 2000; Temple \& cols., 2003), como também na prevenção de ulteriores problemas de leitura (Silva, 2004). Assim, a necessidade de soluções práticas da área na qual se insere é justificativa plausível à realização deste estudo, cujo objetivo foi investigar se a implantação de atividades para desenvolvimento de habilidades metafonológicas pela própria professora, por um período aproximado de 15 a 20 minutos diários, é eficaz em promover desenvolvimento na habilidade de leitura, facilitando a aquisição desta pelas crianças expostas ao procedimento.

Para compreender como essa relação, consciência fonológica e linguagem escrita, se dá, cabe, inicialmente, um breve arrazoado teórico, no qual se tentará delimitar tais conceitos. Gough e Tunmer (1986) compreendem a competência de leitura (L) como um processo resultante da interação entre dois componentes fundamentais, a capacidade específica de decodificação e capacidade geral de compreensão, a qual não se restringe à leitura, envolvendo a compreensão linguística em geral. Descrevendo esses componentes em uma fórmula, os autores sugerem que a capacidade específica de decodificação ou reconhecimento de palavras é "D" e a capacidade linguística geral de compreensão é “ $C$ ”, $\log o$ : $\mathrm{L}=\mathrm{D}$ x C.

Tomando esses dois aspectos, decodificação e compreensão, e sem reduzir a importância fundamental de ambos no processo de leitura, Braibant (1997) ressalta a primazia da decodificação sobre a compreensão, uma vez que, somente quando a decodificação se torna automática, o indivíduo pode liberar recursos atencionais e mnêmicos que, então, atuarão sobre a compreensão do que é lido. Isso se assemelha muito à argumentação de Maluf (2006, setembro) sobre a necessidade de se distinguir "ler" de "aprender a ler". Segundo essa autora, esses são processos inteiramente distintos e não se pode exigir que uma criança tenha acesso ao significado do texto enquanto não há domínio das correspondências 
letra-som, que possibilitam a leitura. Tal equívoco levaria à tentativa de adivinhação do significado, distorcendo a própria concepção do que é "ler".

O desenvolvimento da leitura, no entanto, não se dá de forma natural, sendo necessária uma instrução explícita que facilite essa aquisição. Frith (1997) propõe um modelo atinente às estratégias de leitura. Segundo a autora, antes da alfabetização formal, a leitura é caracterizada pelo uso de pistas contextuais. Nessa estratégia, denominada logográfica, o leitor trata a palavra como um desenho, procedendo a uma "leitura" por reconhecimento visual global.

A segunda estratégia, a alfabética, implica no conhecimento das correspondências entre letras e fonemas durante a codificação e a decodificação. Nessa estratégia, o leitor é capaz de converter o som em escrita (e vice-versa), conseguindo ler e escrever palavras novas e pseudopalavras. Inicialmente, a leitura alfabética pode ser sem compreensão porque, apesar da conversão letra-som, o significado não é alcançado, visto que os recursos centrais de atenção e memória estão totalmente voltados à tarefa de decodificação. Num segundo momento, com a automatização da decodificação, o leitor consegue ter acesso ao significado. Por fim, na estratégia ortográfica, os níveis lexical e morfêmico são reconhecidos diretamente, sem a necessidade de conversão fonológica. Nessa etapa, o leitor já possui um léxico mental ortográfico, podendo relacionar a palavra escrita diretamente ao seu significado, fazendo uma leitura competente. Torna-se possível a leitura de palavras irregulares.

As estratégias de leitura acima mencionadas não são mutuamente excludentes e podem coexistir simultaneamente no leitor e no escritor competentes, sendo que a estratégia a ser usada, em qualquer dado momento, depende do tipo de item a ser lido ou escrito. Ou seja, é influenciada pelas características psicolinguísticas dos itens, tais como lexicalidade, frequência, regularidade grafofonêmica e comprimento (Capovilla \& Capovilla 2004a). Com a conceituação de Ellis e Young (1988) com referência à existência de duas rotas para a leitura, as estratégias alfabética e ortográfica, conforme descrito por Frith, são também designadas como rota fonológica e lexical de leitura, respectivamente.

Diversos autores, como sumariado por Share (1995), sustentam que a rota fonológica é essencial para o desenvolvimento da leitura, uma vez que, no estágio inicial da leitura, o processo de decodificação fonológica é fundamental para a aquisição das representações ortográficas das palavras, o que posteriormente permitirá a leitura via rota lexical. Nos estágios posteriores, a leitura via rota lexical passa a ser mais prevalente, porém a decodificação ainda continua 
sendo de extrema importância, visto que o leitor está sempre deparando palavras desconhecidas. Visto que a rota fonológica é fundamental para a aquisição da leitura e escrita, torna-se também evidente a importância do processamento fonológico e, mais especificamente, da consciência fonológica, pois esta é essencial para os processos de codificação e decodificação na leitura e escrita. Dessa forma, pode-se compreender a eficácia das instruções fônicas e metafonológicas no desenvolvimento de leitura e escrita, pois tais instruções desenvolvem justamente as habilidades fundamentais para o uso competente da rota fonológica.

Por sua vez, a consciência fonológica é definida como a habilidade de refletir sobre a estrutura fonológica da linguagem oral e refere-se ao conhecimento e capacidade de identificar palavras, sílabas, rimas, aliterações e fonemas, compreendendo também a habilidade de discriminar e manipular tais segmentos (Aaron \& cols., 2008; Capovilla \& Capovilla, 2004a; 2004b). Sendo a consciência fonológica um tipo de consciência metalinguística, ao contrário das habilidades linguísticas (como a percepção e discriminação fonêmica), caracteriza-se por ser consciente, intencional e necessitar de instrução formal para ser adquirida, ou seja, a criança precisa receber instrução explícita sobre as regras de mapeamento da escrita alfabética (Morais, 1995).

Juntamente com outras habilidades, por exemplo, nomeação ou consciência sintática, a consciência fonológica faz parte do desenvolvimento normal da linguagem oral, e alguns estudos têm evidenciado a estreita relação entre linguagem oral e linguagem escrita, ou seja, apesar de a linguagem oral e a linguagem escrita serem habilidades relativamente independentes, a linguagem falada serve de base para a aquisição da leitura e da escrita (França \& cols., 2004). De fato, estudos demonstram que tal habilidade está relacionada à aquisição da linguagem escrita (e.g. Cardoso-Martins, 1995; Capovilla \& Capovilla, 2000; 2004a; 2004b), considerando que os processos de conscientização fonológica e de aquisição de leitura e escrita são recíprocos, isto é, facilitam-se mutuamente (Gregóire \& Piérart, 1997).

Anteriormente, discorreu-se sobre o processo de desenvolvimento da leitura e escrita. Agora, compreendendo-se o conceito de consciência fonológica, pode-se também compreender a sua relevância na aquisição e desenvolvimento da leitura e da escrita. Ou seja, a consciência fonológica é habilidade fundamental à adequada decodificação/codificação na leitura/ escrita pela rota fonológica, o que possibilita não somente a leitura de palavras novas ou desconhecidas, mas também a ulterior leitura pela rota lexical. De fato, estudos têm evidenciado que as dificuldades em leitura e escrita se devem, em grande parte, a problemas de processamento fonológico, podendo estes 
ser atenuados e, ou, solucionados com a incorporação de atividades fônicas e metafonológicas em diferentes níveis escolares (Capovilla, 2003), o que tem sido demonstrado em diversas pesquisas (Capovilla \& Capovilla, 2000, 2004a; Temple \& cols., 2003; Schneider \& cols., 1997).

O estudo de Temple e colaboradores (2003), por exemplo, foi conduzido com 20 crianças disléxicas (GE) e 12 crianças leitoras normais (GC), entre 8 e 12 anos de idade. $\mathrm{O}$ estudo constou de três fases: o pré-teste, a intervenção e o pós-teste. Antes e após a intervenção, todas as crianças foram submetidas a escaneamento cerebral por Ressonância Magnética Funcional (fRMI) envolvendo tarefas idênticas para ambos os grupos. As tarefas eram julgamento de rima, combinação de letras e uma tarefa de linha de base com julgamento de linhas. As crianças também foram submetidas, no pré e pós-teste, a uma ampla avaliação de habilidades linguísticas.

O treino supracitado constou de um programa de intervenção computadorizado, sendo que as crianças foram expostas aos exercícios por $100 \mathrm{~min}$ por dia, 5 dias por semana, compondo em média 27,9 dias de treino. $\mathrm{O}$ objetivo do treino foi melhorar o processamento linguístico e auditivo. Era constituído por sete atividades que requeriam diferentes níveis de processamento e consciência fonológica.

As imagens cerebrais pré-intervenção evidenciaram uma resposta neural disfuncional no grupo de crianças disléxicas, em comparação às crianças não disléxicas. Porém o ponto mais interessante deste estudo caracteriza-se pelos efeitos observados após a intervenção. Resumidamente, o teste $t$ de student revelou que as crianças com dislexia tiveram ganhos significativos em habilidades de leitura, decodificação de pseudopalavras e compreensão de leitura, sendo importante destacar que o aumento no desempenho das crianças disléxicas, nessas três medidas, coloca seus escores dentro da faixa de normalidade. As crianças disléxicas também tiveram ganhos em habilidades de linguagem oral e nomeação rápida. Análises das imagens cerebrais após a intervenção revelaram ainda que as crianças com dislexia apresentaram aumento de atividade em várias regióes cerebrais, incluindo o córtex parietotemporal e giro frontal inferior no hemisfério esquerdo, ambas as regióes que apresentaram atividade nas crianças normais durante a performance nas mesmas tarefas, caracterizando o que os autores designaram por efeitos de normalização e confirmando a eficácia de procedimentos interventivos não somente no aumento do desempenho em leitura e outras habilidades como também na promoção de alterações neurofuncionais, aumentando a atividade de regiōes cerebrais envolvidas no processamento fonológico e que não são adequadamente ativadas em crianças disléxicas. Além, foi também observado 
aumento de atividade em áreas cerebrais não ativas nas crianças não disléxicas durante as mesmas tarefas, como o giro frontal inferior, médio e superior e giro temporal médio, no hemisfério direito, caracterizando o que os autores chamaram de efeitos compensatórios.

Em um estudo conduzido com 166 crianças, todas estudantes da $1^{\text {a }}$ série do ensino fundamental (Capovilla, 2002), entre os meses de fevereiro a dezembro, professores de alfabetização de três classes de $1^{\text {a }}$ série (do total de seis classes participantes) foram capacitados a realizar, em sala de aula, um procedimento para desenvolver consciência fonológica. O estudo tinha como objetivo capacitar professores de alfabetização de escolas públicas a fazer uso regular das atividades fônicas em sala de aula e analisar os possíveis ganhos nos desempenhos dos alunos com a introdução de tais atividades na prática escolar, em comparação com programas de alfabetização que não continham instruçôes fônicas sistemáticas. As crianças das seis classes (3 submetidas à intervenção e 3 não submetidas) foram avaliadas em leitura silenciosa, leitura em voz alta, compreensão auditiva, compreensão de leitura, produção de texto, consciência fonológica e escrita. Os resultados mostraram que as crianças submetidas à intervenção fônica tiveram ganhos em praticamente todas as medidas quando comparadas às crianças que continuaram recebendo instruçôes globais, baseadas no texto. Os achados deste estudo sugerem, portanto, que a introdução de instruções fônicas promove um desempenho superior em leitura e escrita em crianças no primeiro ano de alfabetização.

Um estudo complementar de Capovilla (2002) buscou por correlações entre desempenho em leitura e o tempo (em porcentagem) dedicado pelas professoras, em sala de aula, para as atividades fônicas ou globais. Tal estudo evidenciou uma correlação positiva e significativa entre desempenho em leitura e porcentagem de tempo (de 0 a 30\%) dedicado às instruções fônicas. Em relação aos escores, tanto em leitura silenciosa quanto em compreensão de sentenças escritas, os resultados revelaram que o desempenho de leitura das crianças foi diretamente proporcional ao tempo que suas professoras dedicavam ao ensino com base nos fonemas e nas sílabas e inversamente proporcional ao tempo que elas dedicavam ao ensino com base no texto.

Os estudos citados corroboram os pressupostos teóricos apresentados na introdução e reforçam a importância da consciência fonológica para a alfabetização. Do até então exposto, pode-se depreender a relevância de procedimentos interventivos que objetivem desenvolver as habilidades necessárias a um adequado uso da rota fonológica, como a consciência 
fonológica, tal qual a proposta deste breve estudo, provendo, desse modo, ganhos de leitura e facilitando a aquisição desta pelos estudantes participantes.

\section{Método}

\subsection{Participantes}

Participaram deste estudo 1 professora de $1^{\text {a }}$ série e 59 alunos regularmente matriculados em duas classes de $1^{a}$ série do ensino fundamental de uma escola pública de uma cidade do interior do Estado de São Paulo. Uma dessas classes (turno da manhã) foi submetida à intervenção esboçada a seguir ( $\mathrm{GE}=28$ alunos); a outra (turno da tarde) teve sua participação limitada à avaliação final, servindo como parâmetro para as análises atinentes aos efeitos da intervenção ( $\mathrm{GC}=31$ alunos).

\subsection{Material}

Foi usado um procedimento de intervenção para desenvolver consciência fonológica (Capovilla \& Capovilla, 2004a) e ensinar correspondências grafofonêmicas (Capovilla \& Capovilla, 2004b). As atividades integrantes de tal procedimento foram conduzidas utilizando lousa, giz (diversas cores) e, eventualmente, desenhos ou atividades impressas em folha A4. Foi também usado, para avaliação da leitura, ao término do período de intervenção, o "Teste de Competência de Leitura de Palavras e Pseudopalavras" (Capovilla \& Capovilla, 2004b; no prelo). Ambos são descritos a seguir.

\subsection{Procedimento para desenvolver consciência fonológica e ensinar correspondências grafofonêmicas}

Procedimentos para realizar a alfabetização fônica já foram descritos em diversos livros e artigos brasileiros (Capovilla \& Capovilla, 2000, 2004a, 2004b), além de softwares, os quais oferecem estes mesmos procedimentos, porém informatizados, possibilitando um maior engajamento da criança na sua execução (Capovilla, Macedo, Capovilla \& Diana, 2005).

O procedimento interventivo usado pode ser dividido, didaticamente, em duas partes. A primeira se volta ao desenvolvimento da consciência fonológica, habilidade já abordada anteriormente. Cabe, no entanto, relevar que a consciência fonológica abarca desde a consciência de palavras, de sílabas, rimas e aliterações, até a consciência fonêmica. Desse modo, esse procedimento, baseado em Capovilla e Capovilla (2004a), visa a desenvolver 
os diferentes níveis de consciência fonológica, seguindo uma ordem crescente de complexidade. Sendo assim, as atividades foram conduzidas na ordem que segue:

a) consciência de palavras - exemplo: contar quantas palavras há em uma frase, chamar um aluno para representar cada palavra de uma frase ditada, entre outros;

b) consciência de sílabas - exemplo: bater palma a cada sílaba falada de uma palavra, contar as sílabas do próprio nome e ver quem tem o nome maior;

c) rimas - exemplo: pintar somente as figuras que terminem com o som "ão" (utilizando uma folha com desenhos de casa, leão, pão, árvore, fio, coração, navio e mão, por exemplo), falar palavras que rimem com (ou terminem com o som) "ta";

d) aliteração - exemplo: pintar somente as figuras que comecem com o som "ca" (utilizando uma folha com desenhos de caneta, rato, caveira, rosto, cadeira, pé, caderno e ponte, por exemplo), falar palavras que comecem com o som "ma";

e) identidade fonêmica - exemplo: identificar o primeiro som de uma palavra (ffffffaca); dizer palavras que comecem com o som $/ \mathrm{v} /$;

f) consciência fonêmica-exemplo: exercícios de síntese e segmentação fonêmica, como: "que palavra formaremos se juntarmos os sons /g/ $/ \mathrm{a} / \mathrm{t} / / \mathrm{o} /$ ?"

A segunda parte do referido procedimento caracteriza as atividades de ensino de correspondência grafofonêmica, as quais foram baseadas em Capovilla e Capovilla (2004b). Estas têm por objetivo o ensino sistemático e conjunto da letra (seu nome) e seu som. Dessa forma, cada letra foi apresentada à criança juntamente com o seu som. A essa apresentação seguem-se atividades como dizer palavras que comecem com o som aprendido, entre outras.

\subsection{Teste de competência de leitura de palavras e pseudopalavras (TCLPP)}

O "Teste de Competência de Leitura de Palavras e Pseudopalavras" (TCLPP) (Capovilla \& Capovilla, 2004b; no prelo) é um instrumento neuropsicológico e psicométrico para a avaliação da competência de leitura silenciosa. Tem 8 tentativas de treino e 70 de teste, cada qual com um par "figura e item escrito", sendo que a tarefa da criança é marcar com um X os pares figura-escrita incorretos. 
Existem sete tipos de pares, distribuídos aleatoriamente ao longo do teste, com dez itens de teste para cada tipo de par, sendo que os pares figura-escrita compostos de palavras corretas regulares e irregulares devem ser aceitas, enquanto que as de incorreção semântica ou de pseudopalavras devem ser rejeitadas. Conforme descrito por Capovilla e Capovilla (2004b), o padrão de distribuição dos tipos de erros é capaz de indicar as estratégias de leitura usadas. Para compreender a interpretação dos erros, é importante considerar quais estratégias de leitura podem ser usadas para ler cada um dos tipos de pares figura-palavra escrita do TCLPP. Os itens do tipo palavras corretas regulares (ex.: FADA sobre a figura de uma fada), vizinhas semânticas (ex.: TREM sob a figura de ônibus) e pseudopalavras estranhas (ex.: MELOCE sobre a figura de palhaço) podem ser lidas corretamente por qualquer uma das três estratégias, dentre logográfica, alfabética e lexical. Logo, caso o leitor tenha dificuldades em tais itens, isso sugere ausência das três estratégias de leitura. Já as vizinhas visuais (ex.: CAEBÇA sobre a figura de cabeça) e as vizinhas fonológicas (ex.: CANCURU sob a figura de canguru) não podem ser lidas pela estratégia logográfica, mas somente pela alfabética ou ortográfica.

As palavras corretas irregulares (ex.: TÁXI sob a figura de táxi) podem ser lidas pelas estratégias logográfica ou ortográfica, mas não pela alfabética, pois, neste caso, a aplicação das regras de correspondência grafofonêmicas levaria a erros por regularização. Finalmente as pseudopalavras homófonas (ex.: PAÇARU sob a figura de pássaro) somente podem ser lidas corretamente pela estratégia ortográfica, pois, se lidas pela logográfica ou alfabética, tendem a ser aceitas, pois têm forma visual global e auditiva semelhante à palavra correta. Sumariando, o padrão de resposta ao teste tem elevado valor informativo para caracterizar a natureza particular da dificuldade de leitura de um determinado examinando.

\subsection{Procedimento}

Foram conduzidas reuniōes de orientação com a professora da sala da $1^{\text {a }}$ série participante. Tais reuniōes deram-se semanalmente, durante o período escolar regular, enquanto as crianças estavam na aula de artes, com duração entre 45 minutos e 1 hora. No primeiro semestre de 2007, foram realizadas 8 sessóes de orientação e, no segundo semestre do mesmo ano, foram realizadas 9 sessóes, totalizando 17 sessões de orientação, contemplando todo o conteúdo previsto em Capovilla e Capovilla (2004a) e conteúdo parcial (limitando-se às atividades de correspondências grafofonêmica; a intervenção não contemplou atividades de compreensão e produção de textos) de Capovilla e Capovilla (2004b).

Durante esses encontros, foram abordadas as atividades de desenvolvimento de consciência fonológica e de ensino de correspondência grafofonêmicas que a professora conduziria com a sala durante toda a semana. Tais discussões discorreram 
principalmente em como realizar tais atividades no contexto coletivo de sala de aula. As atividades foram conduzidas pela própria professora no decorrer de toda semana, diariamente, com duração de, aproximadamente, 15 a 20 minutos por dia.

De modo geral, tais atividades foram ministradas durante o período de março a outubro de 2007, sendo que, no início do mês de novembro, foram efetuadas as avaliações. Tal avaliação foi coletiva, na própria sala de aula, durante o período escolar regular, com duração aproximada de 40 minutos. Para tal, foi usado o Teste de Competência de Leitura de Palavras e Pseudopalavras. Além da $1^{\text {a }}$ série submetida à intervenção (GE), foi também avaliada outra sala de $1^{\text {a }}$ série, não submetida à intervenção (GC), a qual foi aqui utilizada como parâmetro para as análises subsequentes.

\section{Resultados e discussão}

Inicialmente foram conduzidas análises estatísticas descritivas de modo a determinar a média obtida por cada grupo (grupo controle - GC e grupo experimental - GE) nos escores total e de cada subteste do TCLPP. A tabela 1, a seguir, sumaria esses resultados, apresentando também a média dos escores mínimo e máximo por grupo.

\section{Tabela 1}

Estatísticas descritivas do TCLPP, total e em cada subteste, com escores mínimo, máximo, média e desvio padrão por grupo (GC e GE)

\begin{tabular}{ccccccc}
\hline & GRUPO & $\mathrm{N}$ & $\mathrm{DP}$ & Média & Mínimo & Máximo \\
\hline \multirow{2}{*}{ Total } & GE & 28 & 0,0952 & 0,79 & 0,6 & 0,9 \\
& GC & 31 & 0,1147 & 0,73 & 0,4 & 0,9 \\
CR & GE & 28 & 0,1644 & 0,85 & 0,5 & 1,0 \\
& GC & 31 & 0,2997 & 0,74 & 0,0 & 1,0 \\
CI & GE & 28 & 0,2453 & 0,64 & 0,2 & 1,0 \\
& GC & 31 & 0,2870 & 0,67 & 0,0 & 1,0 \\
VS & GE & 28 & 0,0793 & 0,95 & 0,7 & 1,0 \\
& GC & 31 & 0,1237 & 0,93 & 0,5 & 1,0 \\
VV & GE & 28 & 0,1979 & 0,83 & 0,4 & 1,0 \\
& GC & 31 & 0,2031 & 0,75 & 0,3 & 1,0 \\
VF & GE & 28 & 0,2081 & 0,75 & 0,3 & 1,0 \\
& GC & 31 & 0,2265 & 0,63 & 0,2 & 1,0 \\
PH & GE & 28 & 0,2485 & 0,56 & 0,1 & 1,0 \\
& GC & 31 & 0,2845 & 0,48 & 0,1 & 1,0 \\
PE & GE & 28 & 0,0923 & 0,95 & 0,7 & 1,0 \\
& GC & 31 & 0,1223 & 0,92 & 0,5 & 1,0 \\
\hline
\end{tabular}


Como se pode depreender da tabela 1, o GE obteve melhor desempenho que o GC no TCLPP total e em praticamente todos os seus subtestes, excetuando-se CI. Ou seja, conforme era teoricamente esperado, o grupo submetido à intervenção apresentou melhor desempenho na habilidade de leitura, o que pode ser constatado pela média geral mais elevada. Além, o GE demonstrou melhor eficácia no uso das estratégias de leitura, o que pode ser verificado pelo padrão de erros nos subtestes específicos. Posteriormente, será apresentada uma ilustração gráfica que permite uma melhor compreensão e observação desses resultados.

Além, uma análise das pontuações mínima e máxima obtidas em ambos os grupos permite determinar que estes se assemelham nos escores máximos, ou seja, em ambos os grupos, houve sujeitos que acertaram todos os itens de um subteste, embora nenhum participante de qualquer grupo tenha obtido escore máximo no instrumento (TCLPP Total). Por outro lado, verifica-se que os grupos diferiram entre si no que tange ao escore mínimo ou de solo, no qual se pode constatar que o GE obteve escores mais elevados, sendo que o GC obteve até mesmo escores zero em alguns subtestes (CR e CI). Isso significa dizer que os participantes dessa intervenção cometeram menos erros e constituíram um grupo mais homogêneo no que tange ao desempenho na habilidade de leitura. O GC apresentou maior variabilidade de desempenho, isto é, constitui um grupo mais heterogêneo. Interessantemente, esse efeito já vem sendo relatado em pesquisas análogas, em que o desempenho dos sujeitos considerados "maus leitores" submetidos a intervenções metafonológicas tende a se aproximar do desempenho dos controles considerados "bons leitores" (portanto, tornando o grupo mais homogêneo), enquanto que "maus leitores" não submetidos ao programa tendem a se distanciar cada vez mais dos seus pares "bons leitores" (Capovilla \& Capovilla, 2004a).

De modo a verificar a significância estatística de tais achados, foi conduzido o teste $t$ de Student. A tabela 2 sumaria as estatísticas inferenciais obtidas. Resultados estatisticamente significativos encontram-se destacados em negrito.

Como pode ser observado na tabela 2, a análise revelou diferenças significativas entre os grupos no escore total, $\operatorname{com} p=0,035$. Concernente aos escores em cada subteste, diferenças significativas entre os grupos somente foram evidenciadas em VF, com $p=0,028$. Esses resultados permitem algumas importantes considerações. Em primeiro lugar, considerando a diferença significativa entre grupos no escore total do TCLPP, verifica-se que a intervenção promovida foi eficaz em promover ganhos na habilidade 
de leitura das crianças participantes da intervenção, ou seja, esses resultados evidenciam que o GE desempenhou-se de modo significativamente melhor na tarefa do que o GC.

\section{Tabela 2}

Estatísticas inferenciais do efeito de grupo sobre os escores no TCLPP, total e em cada subteste

\begin{tabular}{lllll}
\hline & & & & \\
& & & $\mathrm{GL}$ & $\mathrm{p}$ \\
\hline \multirow{2}{*}{ TCLPP Total } & Equal variances assumed & 2,165 & 57 & 0,035 \\
CR & Equal variances not assumed & 2,186 & 56,619 & 0,033 \\
& Equal variances assumed & 1,747 & 57 & 0,086 \\
CI & Equal variances not assumed & 1,796 & 47,459 & 0,079 \\
& Equal variances assumed & $-0,412$ & 57 & 0,682 \\
VS & Equal variances not assumed & $-0,415$ & 56,839 & 0,679 \\
& Equal variances assumed & 0,753 & 57 & 0,455 \\
VV & Equal variances not assumed & 0,769 & 51,614 & 0,445 \\
& Equal variances assumed & 1,533 & 57 & 0,131 \\
VF & Equal variances not assumed & 1,535 & 56,659 & 0,130 \\
& Equal variances assumed & 2,248 & 57 & 0,028 \\
PH & Equal variances not assumed & 2,258 & 56,980 & 0,028 \\
& Equal variances assumed & 1,146 & 57 & 0,257 \\
PE & Equal variances not assumed & 1,154 & 56,942 & 0,253 \\
& Equal variances assumed & 1,077 & 57 & 0,286 \\
\hline
\end{tabular}

Com relação aos subtestes, houve diferença significativa entre os grupos em VF. Esse é um dado bastante relevante, uma vez que o cometimento de erros em tais itens é indicativo de falta de acesso ao léxico, com o agravante de possíveis problemas na leitura fonológica. $\mathrm{O}$ fato de esse item ter discriminado ambos os grupos é coerente, uma vez que o foco maior da intervenção realizada foi justamente desenvolver habilidades relacionadas ao adequado uso da rota fonológica. Ou seja, o GE cometeu significativamente menos erros de trocas fonológicas do que o GC, indicando mais um importante ganho da intervenção.

A não ocorrência de níveis estatisticamente significativos nas diferenças observadas entre os escores dos grupos nos demais subtestes não invalida a importância desses achados. Ao contrário, reforça a necessidade de novos 
estudos e de se ponderar sobre uma maior sistematização do procedimento, de modo que este possa ser realizado mais frequentemente e com maior duração das atividades. Porém, de modo geral, este estudo corrobora anteriores, já citados alhures.

De modo a tornar mais fácil a compreensão e a observação desses dados, optou-se por apresentá-los por meio de uma ilustração gráfica. A figura 1 sumaria a média dos escores total e em cada subteste do TCLPP para GE e GC. A sequência dos subtestes é apresentada de acordo com a ordem (decrescente) de desempenho do GE.

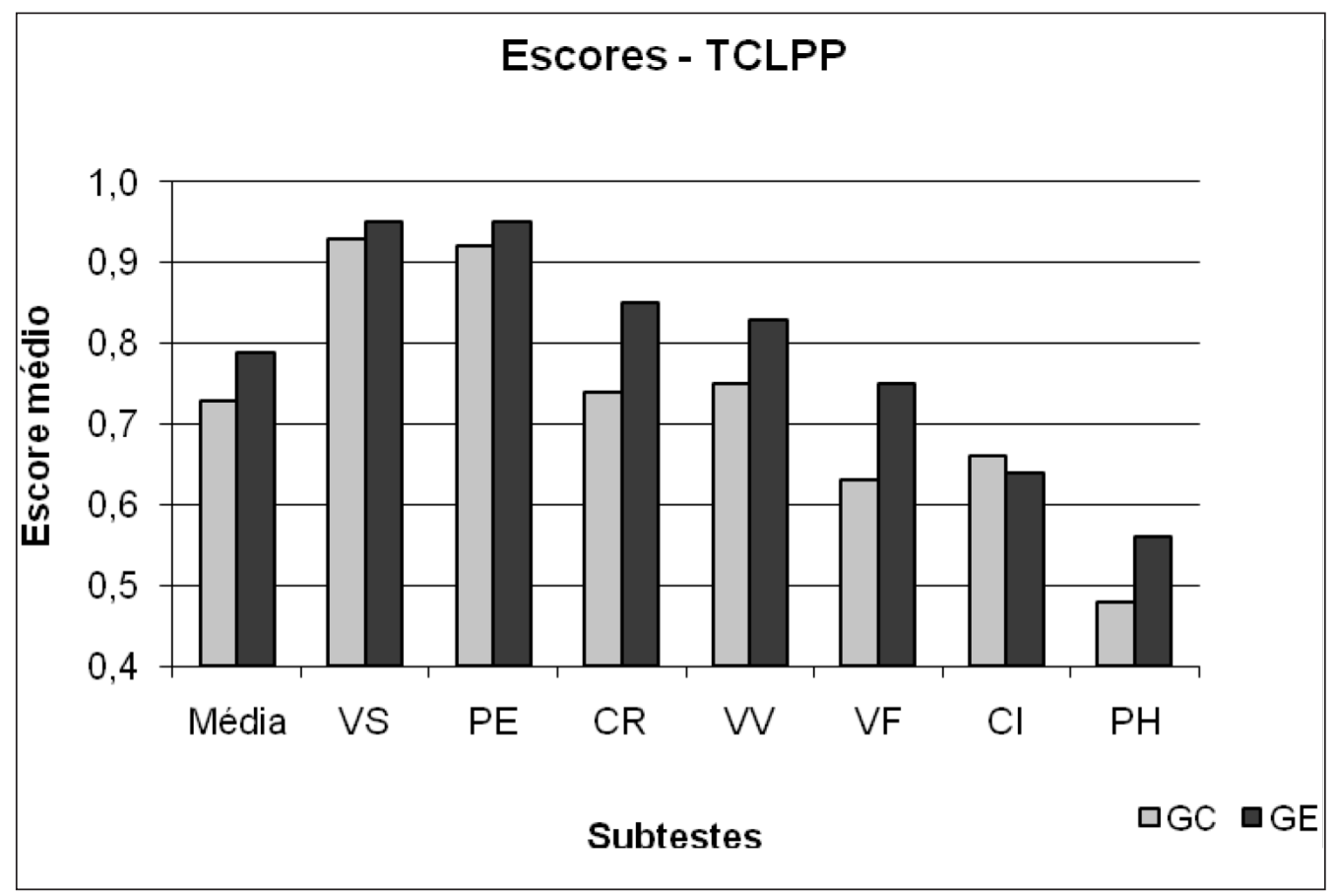

Figura 1. Escores médios no TCLPP para pontuação total e em cada subteste para os grupos controle (GC) e experimental (GE).

Como se pode observar na figura acima, os resultados encontrados são bastante coerentes com o indicado na literatura atinente ao desenvolvimento das estratégias de leitura (Frith, 1997) e dos resultados esperados das intervenções sobre habilidades metacognitivas (Aaron \& cols., 2008; Capovilla \& Capovilla, 2004a; 2004b; Shaywitz, 2006; Temple \& cols., 2003). Além, o padrão de leitura evidenciado é consistente com o achado de estudo prévio (Capovilla \& Dias, 2007). Naquele estudo, que mapeou o desenvolvimento das estratégias de leitura na progressão da $1^{\mathrm{a}}$ à $4^{\mathrm{a}}$ série, a $1^{\mathrm{a}}$ série demonstrou um padrão de leitura predominantemente logográfico, tal qual o GC deste estudo. No que concerne ao GE, esses achados evidenciaram um importante 
desenvolvimento da estratégia alfabética, compondo um padrão de leitura bastante similar ao encontrado no estudo de Capovilla e Dias (2007) somente na $2^{\text {a }}$ série.

Novamente, se observa que o GE obteve melhor desempenho que o GC no TCLPP total e em todos os subtestes, excetuando-se CI, o que pode ser explicado pelo fato de esse tipo de item ser susceptível à leitura pelas estratégias logográfica ou ortográfica, enquanto que o procedimento de intervenção usado tem como objetivo principal desenvolver habilidades de leitura fonológica. Ou seja, as crianças do GE podem ter tentado decodificar esses itens, o que consequentemente pode ter levado a erros de regularização e, portanto, à consideração do item como incorreto, o que também é consistente com o esperado desenvolvimento da estratégia alfabética como resultado da intervenção.

Tomando o gráfico acima apresentado e pautando-se no padrão de desempenho do GE, verifica-se que os itens mais fáceis foram as trocas semânticas, as pseudopalavras estranhas e as palavras corretas regulares, ou seja, itens que podem ser lidos por qualquer uma dentre as três estratégias de leitura: logográfica, alfabética e ortográfica. A seguir, têm-se as trocas visuais e trocas fonológicas, itens mais complexos que requerem leitura fonológica ou lexical, haja vista que, se forem lidas pela estratégia logográfica, podem incorrer em erros de similaridade visual. Por fim, figuram os itens mais complexos, palavras corretas irregulares e pseudopalavras homófonas, as quais requerem necessariamente a leitura lexical. Esses dados, portanto, apontam que a atual amostra tem estratégia logográfica bem estabelecida (GE e GC); estratégia alfabética (leitura fonológica) em desenvolvimento, sobretudo no GE (o que também é corroborado pelo baixo desempenho em $\mathrm{PH}$, indicando que os alunos estão decodificando os itens). O GC ainda apresenta erros importantes em VF, o que fornece indicativos de dificuldades na leitura pela estratégia alfabética. Além, o GC apresenta-se mais propenso a cometer erros pela similaridade visual do item a ser lido (padrão em CR e VV); e estratégia ortográfica (leitura lexical) ainda não desenvolvida ou em estágio bastante incipiente, sobretudo para o GC cujo desempenho em $\mathrm{PH}$ é próximo ao acaso, o que, em conjunto com $\mathrm{CI}$, também é sugestivo de leitura logográfica.

\section{Considerações finais}

À guisa de finalização deste artigo, releva-se que o principal objetivo deste estudo foi atingido. Destarte, o desempenho superior de GE sobre 
GC, assim como o padrão de desempenho dos grupos e suas relativas dificuldades, permite concluir que a intervenção promovida pela professora participante sob a orientação da primeira autora deste artigo foi eficaz em promover ganhos na habilidade de leitura, sobretudo via rota fonológica, e pode, portanto, ser considerada profícua à facilitação da aquisição da linguagem escrita na alfabetização.

De fato, o grupo submetido à intervenção apresentou leitura fonológica (ou estratégia alfabética) relativamente melhor desenvolvida que o grupo controle, o qual apresenta um padrão mais consistente com uma leitura mais pautada na similaridade visual do item escrito. No entanto, com relação ao GE, destaca-se que as habilidades de leitura encontram-se ainda em desenvolvimento e, portanto, a continuidade na administração do procedimento seria bastante apropriada.

Cabe relevar que o estudo contou com algumas limitaçôes metodológicas, como a não realização de uma avaliação pré-intervenção e número amostral limitado, o que pode ter diminuído a extensão da significância estatística dos resultados aqui apresentados. Ainda, faz-se importante destacar que eventos diversos ocorridos no mês de outubro (Semana da Criança, Olimpíadas Estudantis e afastamento da professora pelo período de uma semana) interromperam o andamento da intervenção em diversos momentos, o que pode ter comprometido os resultados. Pesquisas futuras, mais controladas, fazem-se pertinentes, tomando amostras maiores e outros níveis de escolaridade, de modo a ampliar tais achados.

De uma forma geral, o estudo reafirma a eficácia das intervenções pautadas no método fônico no desenvolvimento da habilidade de leitura e a possibilidade de condução de tais atividades pela própria professora, com frequência, porém por períodos curtos e sem prejuízo do conteúdo formal ministrado em sala de aula. Assim, lança contribuições profícuas da Psicologia à Educação.

\section{Referências}

Aaron, P. G.; Joshi, R. M. \& Quatroche, D. (2008). Becoming a professional reading teacher. Baltimore: Paul H. Brookes.

Baker, E. \& Bernhardt, B. (2004). From hindsight to foresight: working around barriers to success in phonological intervention. Child Language Teaching and Therapy, 20 (3), 287-318. 
Braibant, J. M. (1997). A decodificação e a compreensão: dois componentes essenciais da leitura no $2^{\circ}$ ano primário. In: J. Grégoire \& B. Piérart (org.). Avaliação dos problemas de leitura: os novos modelos teóricos e suas implicaçôes diagnósticas. (pp. 167-188). Porto Alegre: Artes Médicas.

Capellini, S. A.; Padula, N. A. M. R. \& Ciasca, S. M. (2004). Desempenho de escolares com distúrbio específico de leitura em programa de remediação. Pró-Fono, 16 (3), 261-274.

Capovilla, A. G. S. (2002). Leitura e escrita como fatores de inclusão: comparando a eficácia dos métodos fônico e global de alfabetização. Psicopedagogia, 19 (60), 4-24.

Capovilla, A. G. S. (2003). A eficácia das instruções fônicas. Revista de Educação CEAP, 40 (11), 56-58.

Capovilla, A. G. S. \& Capovilla, F. C. (2000). Efeitos do treino de consciência fonológica em crianças com baixo nível socioeconômico. Psicologia: Reflexão e Critica, 13 (1), 7-24.

Capovilla, A. G. S. \& Capovilla, F.C. (2004a). Problemas de leitura e escrita: como identificar, prevenir e remediar numa abordagem fônica. São Paulo: Memnon.

Capovilla, A. G. S. \& Capovilla, F. C. (2004b). Alfabetização: método fônico (3. ed.). São Paulo: Memnon.

Capovilla, A. G. S. \& Capovilla, F. C. (no prelo). Teste de leitura de palavra e pseudopalavras. São Paulo: Memnon.

Capovilla, A. G. S. \& Dias, N. M. (2007). Desenvolvimento de estratégias de leitura no ensino fundamental e correlação com nota escolar. Psicologia em Revista, 13 (2), 363-381.

Capovilla, A. G. S. \& Dias, N. M. (submetido). Habilidades de linguagem oral e sua contribuição para a posterior aquisição de leitura. Revista Psic.

Capovilla, A. G. S.; Dias, N. M. \& Montiel, J. M. (2007). Desenvolvimento dos componentes da consciência fonológica no ensino fundamental e correlação com nota escolar. Psico-USF, 12 (1), 55-64.

Capovilla, A. G. S.; Macedo, E. C.; Capovilla, F. C. \& Diana, C. (2005). Alfabetização fônica computadorizada: CD-ROM. São Paulo: Memnon. 
Cardoso-Martins, C. (1995). Sensitivity to rhymes, syllables, and phonemes in literacy acquisition in Portuguese. Reading Research Quarterly, 30 (4), 808828.

Ellis, A. \& Young, A. W. (1988). Human cognitive neuropsychology. London: Lawrence Erlbaum.

França, M. P; Wolff, C. P; Moojen, S. \& Rotta, N. T. (2004). Aquisição da linguagem oral: relação e risco para a linguagem escrita. Arquivos de Neuropsiquiatria, 62 (2b), 469-472.

Frith, U. (1997). Brain, mind and behaviour in dyslexia. In: C. Hulme \& M. Snowling (ed.). Dyslexia: biology, cognition and intervention (pp. 1-19). London: Whurr Publishers.

Gough, P.B. \& Tunmer, W. (1986). Decoding, reading and reading disability. Remedial and Special Education, 7 (1), 6-10.

Grégoire, J. \& Piérart, B. (1997). Avaliação dos problemas de leitura: os novos modelos teóricos e suas implicaçôes diagnósticas. Porto Alegre: Artes Médicas.

Maluf, M.R. (2006). Aprendizagem da linguagem escrita: uma abordagem metalinguistica. Conferência apresentada no II Congresso Brasileiro Psicologia: Ciência e Profissão, São Paulo.

Morais, J. (1995). A arte de ler. São Paulo: Editora Unesp.

Santos, A. A. A. (1996). A influência da consciência fonológica na aquisição da leitura e da escrita. In: F. F. Sisto, G. C. Oliveira, L. D. T. Fini, M. T. C. C. Souza \& R. P. Brenelli (org.). Atuação psicopedagógica e aprendizagem escolar (pp. 213-241). Petrópolis: Vozes.

Share, D. (1995). Phonological recoding and self-teaching: sine qua non of reading acquisition. Cognition, 55 (2), 151-218.

Shaywitz, S. (2006). Entendendo a dislexia: um novo e completo programa para todos os niveis de problemas de leitura. Porto Alegre: Artmed.

Schneider, W.; Kuspert, P.; Roth, E.; Visé, M. \& Marx, H. (1997). Shortand long-term effects of training phonological awareness in kindergarten: Evidence from two German studies. Journal of Experimental Child Psychology, 66, 311-340. 
Silva, A.C. (2004). Descobrir o princípio alfabético. Análise Psicológica, 1 (22), 187-191.

Temple, E.; Deutsch, G. K.; Poldrack, R. A.; Miller, S. L.; Tallal, P.; Merzenich, M. M. \& Gabrieli, J. D. E. (2003). Neural deficits in children with dyslexia ameliorated by behavioral remediation: eidence from functional MRI. PNASProceedings of the National Academy of Sciences of the United States of America, 100 (5), 2860-2865. 